This is a non-final version of an article published in final form in Lee, Andy $\mathrm{H}$. and Pasalich, Maria and Su, Dada and Tang, Li and Tran, Van Dinh and Binns, Colin W. 2013. Mushroom Intake and Risk of Epithelial Ovarian Cancer in Southern Chinese Women. International Journal of Gynecological Cancer. 23 (8): pp. 1400-1405. 
Mushroom intake and risk of epithelial ovarian cancer in southern Chinese women

\author{
Andy H. Lee, PhD,${ }^{1}$ Maria Pasalich, BSc, ${ }^{1}$ Dada Su, MPH, ${ }^{1}$ Li Tang, $\mathrm{MSc}^{1}$, \\ Van Dinh Tran, $\mathrm{MPH}^{2}$ and Colin W. Binns, $\mathrm{PhD}^{1}$
}

${ }^{1}$ School of Public Health, Curtin University, Perth, Australia
${ }^{2}$ Department of Community Health and Network Coordination, National Institute of Hygiene
and Epidemiology, Hanoi, Vietnam

Corresponding author:

Professor Andy H. Lee

School of Public Health

Curtin University

GPO Box U 1987

Perth, WA, 6845

Australia

Phone: +61-8-92664180

Fax: $+61-8-92662958$

Email: Andy.Lee@curtin.edu.au

Sources of support: The study was supported by Curtin University. The authors declare no conflicts of interest. 


\title{
Mushroom intake and risk of epithelial ovarian cancer in southern Chinese women
}

\begin{abstract}
Objective: To investigate the association between mushroom consumption and risk of epithelial ovarian cancer in southern Chinese women.
\end{abstract}

Methods: A hospital-based case-control study was undertaken in Guangzhou, Guangdong Province, from 2006 to 2008. Participants were 500 incident epithelial ovarian cancer patients and 500 controls, with a mean age 59 (SD 6) years. Information on habitual mushroom consumption was obtained by face-to-face interview using a validated and reliable food frequency questionnaire. Unconditional logistic regression analyses were performed to assess the association between mushroom intake and the ovarian cancer risk.

Results: The ovarian cancer patients consumed less mushrooms (mean 28.48, SD 37.45 $\mathrm{g}$ /day) than controls (mean 30.75, SD $41.85 \mathrm{~g} /$ day). Apparent reductions in cancer risk were found at high levels of intake, especially for the common white button mushroom with adjusted odds ratios 0.68 (95\% confidence interval 0.52 to 0.89 ) for women consuming more than $2 \mathrm{~g}$ per day relative to those below, $\mathrm{p}=0.005$. Decreases in risk at high levels of intake were also observed for serous and mucinous subtypes of epithelial ovarian tumours.

Conclusions: Intake of mushrooms particularly white button mushroom appeared to be inversely associated with the incidence of epithelial ovarian cancer in southern Chinese women.

Keywords: China; Epithelial ovarian cancer; Mushroom. 


\section{INTRODUCTION}

Ovarian cancer is the second most common gynaecological malignancy ${ }^{(1)}$. Approximately $90 \%$ of ovarian malignancies are epithelial in origin ${ }^{(2)}$. The disease is generally diagnosed at an advanced stage, as the symptoms are vague and non-specific ${ }^{(3)}$. The incidence of ovarian cancer varies substantially across geographical regions, with higher rates generally observed in developed countries. For example, the age-standardised rates in China is 3.8 per 100,000 women, much lower than those of developed countries such as the USA (8.8) and Australia $(7.7)^{(4)}$. The large variations in incidence rates between countries may be attributed to differences in dietary and lifestyle habits in ovarian cancer aetiology, besides genetic and familial risk factors.

Previous research has reported the protective effects of vegetables, fruit and soy foods ${ }^{(5-7)}$, whereas consumption of meat and preserved foods may contribute to the development of ovarian cancer ${ }^{(8,9)}$. For thousands of years, mushrooms have been valued for their medicinal properties. Some dietary supplements contain mushroom extracts and claim to improve immune functions ${ }^{(10)}$. However, there have been limited epidemiological studies that investigated the association between edible mushroom and cancer risk ${ }^{(11-16)}$, the majority of which were conducted on Asian populations. The available evidence suggested that increased mushroom intake may reduce the risk of gastric cancer ${ }^{(11,12)}$ and breast cancer ${ }^{(13-16)}$, but there is still no published report assessing mushroom intake in relation to ovarian cancer.

China is the biggest mushroom consumption market. An increasing number of urban Chinese consumers are replacing meat products with mushrooms ${ }^{(17)}$. In southern China, several species of mushroom are used in local cuisines, including the white button mushroom 
(Agaricus bisporus), straw mushroom (Volvariella volvacea) and Chinese black (shiitake) mushroom, the latter being sun dried and are soaked in water before cooking. In view of the lack of epidemiological evidence, the present study investigated the association between habitual mushroom consumption and the risk of epithelial ovarian cancer among southern Chinese women. The study formed part of a research project assessing the role of dietary and lifestyle factors for the prevention of this major disease.

\section{MATERIALS AND METHODS}

\section{Study design and subjects}

A case-control design was used to study risk factors associated with ovarian cancer in the Guangdong Province of southern China, between August 2006 and July 2008. Cases and controls were recruited from four public hospitals located in Guangzhou: The Overseas Hospital (affiliated with Jinan University), Zhujiang Hospital, General Hospital of Guangzhou Military Command, and Second Affiliated Hospital of Zhongshan University. The cases were incident patients who had been histopathologically diagnosed with epithelial ovarian cancer. Controls were recruited from inpatient wards of the Departments of Ophthalmology, Orthopedics, Respiratory Disease, Gastroenterology and Physiotherapy. The inclusion criteria for all subjects were less than 75 years of age and to have resided in the metropolitan Guangzhou area for the past ten years or more. Participants were also excluded if the medical staff advised that they were too ill to participate or had severe memory impairment that precluded their recall of risk factors.

Potential cases were identified by searching all medical records and laboratory pathology reports at the participating hospitals on a daily basis during the recruitment period. The International Histological Classification of Ovarian Tumors was used to categorize all of the 
ovarian tumours ${ }^{(18)}$. Patients were excluded if a diagnosis of ovarian cancer was not histopathologically confirmed as the diagnosis, or if the subject had memory problems affecting their recall of past events. A total of 504 cases consecutively recruited from the four hospitals were eligible to participate and 500 patients ( $99.2 \%$ consent rate) gave their consent to participate and were capable of being interviewed.

During the same period, 512 potential controls satisfying the age and residency criteria were identified and were invited to participate. The controls were frequency matched to cases by age ( \pm 5 years). Exclusion criteria for controls were: previous diagnosis of ovarian cancer or other malignant diseases; a history of bilateral oophorectomy; on a long-term modified diet for medical reasons; having memory problems. Potential controls were initially identified using the hospital daily census sheets. A selection of wards and patients to be screened was made using random numbers each day whenever an excess of control subjects, more than could be interviewed, were available. All eligible inpatients had their diagnosis subsequently confirmed by histopathological reports to avoid misclassification of the case-control status. This systematic selection process was used for the duration of the recruitment period. Twelve women who declined the interview or not satisfying the eligibility conditions were later excluded, resulting in a final sample of 500 controls (97.6\% response) available for analysis. No statistically significant differences were found between the two groups in terms of age and main demographic variables.

\section{Interview}

Appointments for face-to-face interview at the ward were made after consulting the nursing staff to avoid interference with treatment. Whenever possible, subjects were interviewed in the presence of their next-of-kin to help in the recall of past dietary habits. All participants 
were read an information sheet giving details of the study and were assured of confidentiality and their right to withdraw at any time without prejudice. They were then asked to give formal consent before the interview commenced. Each interview was conducted in either Mandarin or the Cantonese dialect and took about 45 minutes to complete. All participants were blinded to the study hypothesis. The project protocol was approved by the participating hospitals, the doctors-in-charge of the relevant wards, and the Human Research Ethics Committee of the researchers' institution (approval number HR 78/2006).

\section{Questionnaire and exposure measurements}

A structured questionnaire was administered to obtain demographic and lifestyle characteristics including age, weight $(\mathrm{kg})$, height $(\mathrm{m})$, education level, smoking status and alcohol consumption, as well as reproductive history, hormonal status and heredity. Selfreported data were cross-checked with medical records whenever possible.

Participants were also requested to estimate the average time they had engaged in physical activities using a validated questionnaire ${ }^{(19)}$. Intensity was classified by the amount of energy or effort a person expends in performing the activity. Physical activity at each intensity level was quantified in terms of metabolic equivalent tasks (MET)-hours per week, with intensity codes 7.5, 6.0 and 4.5 MET assigned to strenuous sports, vigorous work and moderate activity, respectively. Total physical activity was then calculated by summing the product of the MET scores and the activity duration over the three intensity levels.

Information on habitual food and beverage consumption was obtained using a 125-item semiquantitative food frequency questionnaire developed and tested in a southern Chinese population ${ }^{(20,21)}$. This validated instrument covers commonly consumed foods (including 
mushrooms) in southern China. Each subject was asked to record in detail the frequency and amount of food eaten or drunk. The reference recall period for dietary variables was set at five years before diagnosis for cases and five years before interview for controls. The energy content of each food or beverage item was obtained from the Chinese food composition tables ${ }^{(22)}$. We then estimated participant's total energy intake (kcal) by summing the energy intake across all of the individual items consumed.

\section{Statistical analysis}

Descriptive statistics were first applied to summarize the sample characteristics. Total mushroom intake (g/day) was defined as the sum of daily consumption of white button, straw and Chinese black mushrooms. Case and control groups were compared in terms total and individual mushrooms intake. Unconditional logistic regression analyses were then performed to investigate the effects of habitual mushroom consumption on the ovarian cancer risk. Each consumption variable was dichotomized into low and high levels of exposure with cutoff points determined based on the distribution of controls, due to their relatively low amount of daily intake. To investigate the risk of ovarian cancer by specific histologic subtype, we compared selected case subtype to the entire control group using adjusted odds ratios (OR) and associated $95 \%$ confidence intervals (CI). Confounding variables included in the logistic regression models were age at interview (years), age of menarche (years), parity, oral contraceptive use (never, ever), body mass index (5 years ago), menopausal status (pre, post), education level (none or primary, secondary, vocational or tertiary), tobacco smoking (never, ever), alcohol drinking (no, yes), physical activity (MET-hours/week), total energy intake (kcal/day), and family history of ovarian or breast cancer (no, yes). These variables were either established or plausible risk factors from the literature. All statistical analyses were undertaken using the SPSS package version 20. 


\section{RESULTS}

Half of the 500 epithelial ovarian tumours were classified as serous (50\%), followed by mucinous (16\%), borderline (13\%), and undifferentiated carcinoma $(11.8 \%)$. The other histologic subtypes (endometrioid, mixed, clear cell, transitional cell, malignant Brenner's tumour) made up the remaining $9.2 \%$ of the cases. Table 1 presents the sample characteristics by case-control status. The participants were on average 59 (SD 6) years of age and predominantly post-menopausal (95\%). Most of them had secondary school or above education (60\%), were non-smokers $(97 \%)$ and seldom drank alcoholic beverages on a regular basis $(72 \%)$. Very few women $(3.5 \%)$ had a family history of ovarian or breast cancer. However, women with ovarian cancer appeared to have less oral contraceptive use and lower parities $(\mathrm{p}<0.01)$ but higher mean body mass index $(\mathrm{p}<0.01)$ than their counterparts without the disease. They also tended to be less physically active in daily life ( $\mathrm{p}$ $<0.01)$.

Table 2 compares habitual mushroom consumption between case and control groups. The ovarian cancer patients reported lower total mushroom intake (mean 28.48, SD $37.45 \mathrm{~g} /$ day) than the control subjects (mean 30.75, SD 41.85 g/day). Indeed, lower levels of consumption were observed across all three types of mushroom, but such differences attained statistical significance $(\mathrm{p}<0.05)$ only for the white button mushroom.

Table 3 summarizes the results of logistic regression analyses. Apparent reductions in ovarian cancer risk were achieved at high levels of total and individual mushroom intake, especially for white button mushroom with adjusted OR 0.68 (95\% CI 0.52 to 0.89 ) for women consuming more than $2 \mathrm{~g}$ per day relative to those below, $\mathrm{p}=0.005$. Decreases in risk at high 
levels of intake were similarly found among serous and mucinous subtypes of epithelial ovarian tumours. Analyses were not performed for other histologic subtypes due to the low number of cases available.

\section{DISCUSSION}

The present study provides the first epidemiological report on the association between mushroom intake and epithelial ovarian cancer risk. A major strength was the implementation of a standardized identification procedure which ensured that ascertainment of cases was maximized and complete. To avoid misclassification of the case-control status, we recruited only incident patients who had been histopathologically diagnosed with epithelial ovarian cancer within the past 12 months. Meanwhile, all controls were carefully screened and subsequently confirmed with pathology. A high response rate (98\%) was achieved in the recruitment of inpatients through assistance by the hospital medical staff. Another strength concerned habitual mushroom consumption, which was measured using a validated and reliable questionnaire developed for the southern Chinese population. To determine and ascertain the effect of mushroom intake, information on confounding factors such as tobacco smoking, alcohol drinking and physical activity was also collected. It is possible that some ovarian cancer patients may modify their dietary habits since the onset of the disease. Therefore, the reference period for habitual mushroom consumption was set at five years before diagnosis for cases and five years before interview for controls in order to avoid reverse causation. In this study, no participant reported any change in eating habits for medical reasons within the past five years.

Our results suggested that mushroom intake at high levels was associated with a reduced risk of epithelial ovarian cancer among southern Chinese women, particularly for the common 
Agaricus bisporus mushroom. Similar inverse associations have been reported for gastric and breast cancers ${ }^{(11-16)}$. Mushrooms are high in fibre, vitamins and minerals such as vitamin B, potassium, and phosphorus ${ }^{(23)}$. They also contain bioactive compounds, including antitumour polysaccharides ${ }^{(24)}$. Animal studies have reported on the anti-carcinogenic effect of various mushroom species. For example, lectins isolated from mushroom could activate macrophages and inhibit the growth of implanted cancer cells in mice ${ }^{(25)}$, while phytochemicals present in white button mushroom extracts have been found to inhibit aromatase activity and proliferation in breast cancer cell lines ${ }^{(26-28)}$. These phytochemicals also affect free radical scavenging activity and inhibition of oxidative stress ${ }^{(29,30)}$. Other potential mechanisms include suppression of DNA synthesis, altering membrane structure and competing for oestrogen receptors ${ }^{(26)}$.

In this study, Chinese black mushroom and white button mushroom appeared to have their respective effect on mucinous and serous subtypes of epithelial ovarian tumours. A high level of cholesterol is known to elevate the risk of mucinous ovarian neoplasm ${ }^{(31)}$. Chinese black mushroom contains the cholesterol reducing compound eritadenine ${ }^{(32)}$, which may protect against the development of mucinous tumours. On the other hand, vitamin D, which is present in white button mushroom but not in Chinese black mushroom, has been shown to inhibit serous ovarian tumours ${ }^{(33)}$. Nevertheless, further experimental studies are needed to understand the biological mechanisms underlying the protective effects of these mushrooms against ovarian cancer.

There are several limitations in this study. Firstly, cause-effect relationship between mushroom intake and ovarian cancer prevention could not be established due to the inherent retrospective study design. Secondly, dietary assessment was based on self-report so that 
responses from participants would inevitably incur some recall error, even though the recall of habitual mushroom consumption should not be affected by the case-control status. Therefore, face-to-face interviews were conducted in the presence of next-of-kin to help memory recall and to improve the accuracy of their answers. Thirdly, selection bias was unavoidable because of voluntary participation, while the hospital-based controls were not randomly selected from the community. Nevertheless, the four participating hospitals serve the entire catchment region so that our subjects were still representative of the target population. Recruitment bias was also minimized by sampling from different hospitals. Fourthly, information bias and recall bias were unlikely because all participants were blind to the study hypothesis, while the protective effects of mushroom on ovarian cancer have not been established. Finally, residual confounding might still exist even after controlling for established risk factors in the multivariable logistic regression analyses. There is no evidence from the literature supporting consumption of mushroom as a marker of healthy lifestyle among southern Chinese women.

In conclusion, a moderate inverse association was found between habitual mushroom intake and epithelial ovarian cancer incidence in southern China. Replications in other countries and large scale prospective cohort studies are required to confirm the effects of long term consumption.

\section{ACKNOWLEDGMENTS}

We are grateful to the patients and medical and nursing staff from the participating hospitals for their cooperation in the study. 
Table 1. Characteristics of participants by case-control status

\begin{tabular}{|c|c|c|c|}
\hline Variable & $\begin{array}{l}\text { Cases } \\
\mathrm{n}(\%)\end{array}$ & $\begin{array}{c}\text { Controls } \\
\text { n }(\%)\end{array}$ & $p^{a}$ \\
\hline Education level & & & 0.90 \\
\hline None/primary & $204(40.8 \%)$ & $197(39.4 \%)$ & \\
\hline Secondary & $171(34.2 \%)$ & $175(35.0 \%)$ & \\
\hline Vocational/tertiary & $125(25.0 \%)$ & $128(25.6 \%)$ & \\
\hline Smoking status & & & 0.49 \\
\hline Never & $481(96.2 \%)$ & $485(97.0 \%)$ & \\
\hline Ever & $19(3.8 \%)$ & $15(3.0 \%)$ & \\
\hline Alcohol drinking & & & 0.16 \\
\hline No & $352(70.4 \%)$ & $372(74.4 \%)$ & \\
\hline Yes & $148(29.6 \%)$ & $128(25.6 \%)$ & \\
\hline Parity & & & $<0.01$ \\
\hline 0 & $8(1.6 \%)$ & $14(2.8 \%)$ & \\
\hline 1 & $172(34.4 \%)$ & $143(28.6 \%)$ & \\
\hline 2 & $219(43.8 \%)$ & $176(35.2 \%)$ & \\
\hline$\geq 3$ & $101(20.2 \%)$ & $167(33.4 \%)$ & \\
\hline Oral contraceptive use & & & $<0.01$ \\
\hline Never & $417(83.4 \%)$ & $380(76.0 \%)$ & \\
\hline Ever & $83(16.6 \%)$ & $120(24.0 \%)$ & \\
\hline Menopausal status & & & 0.24 \\
\hline Pre & $28(5.6 \%)$ & $20(4.0 \%)$ & \\
\hline Post & $472(94.4 \%)$ & $480(96.0 \%)$ & \\
\hline
\end{tabular}




\begin{tabular}{|l|c|c|c|}
\hline Family history of ovarian or breast cancer & & & 0.39 \\
\hline No & $480(96.0 \%)$ & $485(97.0 \%)$ & \\
\hline Yes & $20(4.0 \%)$ & $15(3.0 \%)$ & \\
\hline Age at interview (years): mean (SD) & $59.07(5.68)$ & $59.71(6.46)$ & 0.10 \\
\hline Age of menarche (years): mean (SD) & $14.68(1.60)$ & $14.70(1.80)$ & 0.88 \\
\hline Body mass index (5 years ago, kg/m $\left.{ }^{2}\right):$ & $21.70(2.54)$ & $21.12(2.28)$ & $<0.01$ \\
mean (SD) & & & \\
\hline Physical activity (MET-hours/week): & $16.21(14.1)$ & $18.84(13.0)$ & $<0.01$ \\
mean (SD) & & & \\
\hline
\end{tabular}

${ }^{a}$ Chi-square or t-test for difference between cases and controls 
Table 2. Comparison of mushroom consumption between case and control groups

\begin{tabular}{|c|c|c|c|c|}
\hline & & Cases & & Controls \\
\hline Daily intake (g) & $\begin{array}{c}\text { All } \\
(\mathrm{n}=500) \\
\text { mean (SD) }\end{array}$ & $\begin{array}{c}\text { Serous } \\
(\mathrm{n}=250) \\
\text { mean }(\mathrm{SD})\end{array}$ & $\begin{array}{l}\text { Mucinous } \\
(\mathrm{n}=80) \\
\text { mean (SD) }\end{array}$ & $\begin{array}{c}(\mathrm{n}=500) \\
\text { mean }(\mathrm{SD})\end{array}$ \\
\hline Total mushroom & $\begin{array}{c}28.48 \\
(37.45)\end{array}$ & $\begin{array}{c}27.98 \\
(34.35)\end{array}$ & $\begin{array}{c}26.71 \\
(42.18)\end{array}$ & $\begin{array}{c}30.75 \\
(41.85)\end{array}$ \\
\hline $\begin{array}{l}\text { White button } \\
\text { mushroom }\end{array}$ & $\begin{array}{l}3.09 * \\
(4.18)\end{array}$ & $\begin{array}{l}2.78 * * \\
(3.42)\end{array}$ & $\begin{array}{l}2.96 * \\
(2.98)\end{array}$ & $\begin{array}{c}4.07 \\
(5.75)\end{array}$ \\
\hline Straw mushroom & $\begin{array}{l}4.00 \\
(7.83)\end{array}$ & $\begin{array}{c}3.99 \\
(5.75)\end{array}$ & $\begin{array}{c}4.89 \\
(11.54)\end{array}$ & $\begin{array}{c}4.33 \\
(8.97)\end{array}$ \\
\hline $\begin{array}{l}\text { Chinese black } \\
\text { mushroom }\end{array}$ & $\begin{array}{c}21.38 \\
(31.47)\end{array}$ & $\begin{array}{l}21.21 \\
(30.17)\end{array}$ & $\begin{array}{c}18.86 \\
(32.29)\end{array}$ & $\begin{array}{l}22.35 \\
(32.96)\end{array}$ \\
\hline
\end{tabular}

$* \mathrm{p}<0.05, * * \mathrm{p}<0.001$ for $\mathrm{t}$-test between cases and controls 
Table 3. Adjusted odds ratios (95\% confidence intervals) of epithelial ovarian cancer risk for mushroom intake in southern Chinese women

\begin{tabular}{|c|c|c|c|c|c|c|c|}
\hline \multirow{3}{*}{\begin{tabular}{|l|} 
\\
$\begin{array}{l}\text { Daily } \\
\text { intake (g) }\end{array}$
\end{tabular}} & \multicolumn{6}{|c|}{ Cases } & \multirow{3}{*}{$\begin{array}{c}\text { Controls } \\
\begin{array}{c}(\mathrm{n}=500) \\
\mathrm{n}(\%)\end{array}\end{array}$} \\
\hline & \multicolumn{2}{|c|}{ All $(n=500)$} & \multicolumn{2}{|c|}{ Serous $(n=250)$} & \multicolumn{2}{|c|}{ Mucinous $(n=80)$} & \\
\hline & $\mathrm{n}(\%)$ & $\begin{array}{c}\text { Adjusted } \\
\text { OR }^{\mathrm{a}} \\
(95 \% \mathrm{CI})\end{array}$ & $\mathrm{n}(\%)$ & $\begin{array}{l}\text { Adjusted } \\
\text { OR }^{\mathrm{a}} \\
(95 \% \mathrm{CI})\end{array}$ & $\mathrm{n}(\%)$ & $\begin{array}{l}\text { Adjusted } \\
\text { OR }^{\mathrm{a}} \\
(95 \% \mathrm{CI})\end{array}$ & \\
\hline $\begin{array}{l}\text { Total } \\
\text { mushroom }\end{array}$ & & $\mathrm{p}=0.055$ & & $p=0.104$ & & $\mathrm{p}=0.238$ & \\
\hline$\leq 14$ & $\begin{array}{c}237 \\
(47.4 \%)\end{array}$ & 1 & $\begin{array}{c}122 \\
(48.8 \%)\end{array}$ & 1 & $\begin{array}{c}38 \\
(47.5 \%)\end{array}$ & 1 & $\begin{array}{c}211 \\
(42.2 \%)\end{array}$ \\
\hline$>14$ & $\begin{array}{c}263 \\
(52.6 \%)\end{array}$ & $\begin{array}{c}0.76 \\
(0.58,1.01)\end{array}$ & $\begin{array}{c}128 \\
(51.2 \%)\end{array}$ & $\begin{array}{c}0.75 \\
(0.53,1.06)\end{array}$ & $\begin{array}{c}42 \\
(52.5 \%)\end{array}$ & $\begin{array}{c}0.73 \\
(0.44,1.23)\end{array}$ & $\begin{array}{c}289 \\
(57.8 \%)\end{array}$ \\
\hline $\begin{array}{l}\text { White } \\
\text { button } \\
\text { mushroom }\end{array}$ & & $\mathrm{p}=0.005$ & & $\mathrm{p}=0.006$ & & $p=0.626$ & \\
\hline$\leq 2$ & $\begin{array}{c}282 \\
(56.4 \%)\end{array}$ & 1 & $\begin{array}{c}148 \\
(59.2 \%)\end{array}$ & 1 & $\begin{array}{c}40 \\
(50 \%)\end{array}$ & 1 & $\begin{array}{c}233 \\
(46.6 \%)\end{array}$ \\
\hline$>2$ & $\begin{array}{c}218 \\
(43.6 \%)\end{array}$ & $\begin{array}{c}0.68 \\
(0.52,0.89)\end{array}$ & $\begin{array}{c}102 \\
(40.8 \%)\end{array}$ & $\begin{array}{c}0.62 \\
(0.44,0.87)\end{array}$ & $\begin{array}{c}40 \\
(50 \%)\end{array}$ & $\begin{array}{c}0.88 \\
(0.54,1.45)\end{array}$ & $\begin{array}{c}267 \\
(53.4 \%)\end{array}$ \\
\hline $\begin{array}{l}\text { Straw } \\
\text { mushroom }\end{array}$ & & $\mathrm{p}=0.180$ & & $\mathrm{p}=0.500$ & & $p=0.066$ & \\
\hline$\leq 2$ & $\begin{array}{c}69 \\
(13.8 \%)\end{array}$ & 1 & $\begin{array}{c}32 \\
(12.8 \%)\end{array}$ & 1 & $\begin{array}{c}14 \\
(17.5 \%)\end{array}$ & 1 & $\begin{array}{c}56 \\
(11.2 \%)\end{array}$ \\
\hline$>2$ & $\begin{array}{c}431 \\
(86.2 \%)\end{array}$ & $\begin{array}{c}0.76 \\
(0.51,1.14)\end{array}$ & $\begin{array}{c}218 \\
(87.2 \%)\end{array}$ & $\begin{array}{c}0.84 \\
(0.50,1.40)\end{array}$ & $\begin{array}{c}66 \\
(82.5 \%)\end{array}$ & $\begin{array}{c}0.53 \\
(0.26,1.04)\end{array}$ & $\begin{array}{c}444 \\
(88.8 \%)\end{array}$ \\
\hline
\end{tabular}




\begin{tabular}{|l|c|c|c|c|c|c|c|}
\hline $\begin{array}{l}\text { Chinese } \\
\text { black } \\
\text { mushroom }\end{array}$ & $\mathrm{p}=0.035$ & & $\mathrm{p}=0.275$ & & $\mathrm{p}=0.002$ & \\
\hline$\leq 8$ & 62 & 1 & 27 & 1 & 15 & 1 & 50 \\
& $(12.4 \%)$ & $(10.8 \%)$ & & $(18.8 \%)$ & & $(10 \%)$ \\
\hline$>8$ & 438 & 0.63 & 223 & 0.73 & 65 & 0.33 & 450 \\
& $(87.6 \%)$ & $(0.41,0.97)$ & $(89.2 \%)$ & $(0.42,1.28)$ & $(81.3 \%)$ & $(0.16,0.67)$ & $(90 \%)$ \\
\hline
\end{tabular}

${ }^{a}$ From separate logistic regression models adjusting for age at interview (years), age of menarche (years), body mass index (5 years ago, $\mathrm{kg} / \mathrm{m}^{2}$ ), physical activity (METhours/week), total energy intake (kcal/day), parity, oral contraceptive use (never, ever), menopausal status (pre, post), education level (none/primary, secondary, vocational/tertiary), smoking status (never, ever), alcohol drinking (no, yes), and family history of ovarian or breast cancer (no, yes). 


\section{REFERENCES}

[1] Sankaranarayanan R, Ferlay J. Worldwide burden of gynaecological cancer: the size of the problem. Best Pract Res Clin Obstet Gynaecol. 2006;20: 207-25.

[2] Cho K, Shih I. Ovarian cancer. Annu Rev Pathol. 2009;4: 287-313.

[3] Lutz AM, Willmann JK, Drescher CW et al. Early diagnosis of ovarian carcinoma: is a solution in sight? Radiology. 2011;259: 329-45.

[4] Ferlay J, Shin H, Bray F et al. Cancer incidence and mortality worldwide. Lyon, France: International Agency for Research on Cancer 2010.

[5] Zhang M, Yang ZY, Binns CW, Lee AH. Diet and ovarian cancer risk: a case-control study in China. Br J Cancer. 2002;86: 712-7.

[6] Zhang M, Xie X, Lee AH, Binns CW. Soy and isoflavone intake are associated with reduced risk of ovarian cancer in southeast China. Nutr Cancer. 2004;49: 125-30.

[7] Myung SK, Ju W, Choi HJ et al. Soy intake and risk of endocrine-related gynaecological cancer: a meta-analysis. BJOG. 2009;116: 1697-705.

[8] Kolahdooz F, van der Pols JC, Bain CJ et al. Meat, fish, and ovarian cancer risk: Results from 2 Australian case-control studies, a systematic review, and meta-analysis. Am J Clin Nutr. 2010;91: 1752-63.

[9] Kiani F, Knutsen S, Singh P et al. Dietary risk factors for ovarian cancer: the Adventist Health Study (United States). Cancer Causes Control. 2006;17: 137-46. [10] Borchers AT, Stern JS, Hackman RM et al. Mushrooms, tumors, and immunity. Proceedings of the Society for Experimental Biology and Medicine Society for Experimental Biology and Medicine (New York, NY). 1999;221: 281-93.

[11] Kim HJ, Chang WK, Kim MK et al. Dietary factors and gastric cancer in Korea: a case-control study. Int J Cancer. 2002;97: 531-5. 
[12] Hara M, Hanaoka T, Kobayashi M et al. Cruciferous vegetables, mushrooms, and gastrointestinal cancer risks in a multicenter, hospital-based case-control study in Japan. Nutr Cancer. 2003;46: 138-47.

[13] Lee S-A, Kang D, Nishio H et al. Methylenetetrahydrofolate reductase polymorphism, diet, and breast cancer in Korean women. Exp Mol Med. 2004;36: 116-21.

[14] Hong SA, Kim K, Nam S-J et al. A case-control study on the dietary intake of mushrooms and breast cancer risk among Korean women. Int J Cancer. 2008;122: 919-23. [15] Zhang M, Huang J, Xie X, Holman CDAJ. Dietary intakes of mushrooms and green tea combine to reduce the risk of breast cancer in Chinese women. Int J Cancer. 2009;124: 1404-8.

[16] Shin A, Kim J, Lim S-Y et al. Dietary mushroom intake and the risk of breast cancer based on hormone receptor status. Nutr Cancer. 2010;62: 476-83.

[17] Mushroom Business. Mushroom economics in China. 2011.

[18] Heintz AP, Odicino F, Maisonneuve P et al. Carcinoma of the ovary. FIGO (International Federation of Gynecology and Obstetrics) 26th Annual Report on the Results of Treatment in Gynecological Cancer. Int J Gynaecol Obstet. 2006;95 Suppl 1: S161-S92. [19] Jian L, Shen ZJ, Lee AH, Binns CW. Moderate physical activity and prostate cancer risk: a case-control study in China. Eur J Epidemiol. 2005;20: 155-60.

[20] Ke L, Toshiro T, Fengyan S et al. Relative validity of a semi-quantitative food frequency questionnaire versus 3 day weighed diet records in middle-aged inhabitants in Chaoshan area, China. Asian Pac J Cancer Prev. 2005;6: 376-81.

[21] Song FY, Toshiro T, Li K et al. Development of a semi-quantitative food frequency questionnaire for middle-aged inhabitants in the Chaoshan area, China. World $J$ Gastroenterol. 2005;11: 4078-84. 
[22] Yang Y, Wang G, Pan X. China Food Composition Table: Peking University Medical Press 2002.

[23] Mattila P, Könkö K, Eurola M et al. Contents of vitamins, mineral elements, and some phenolic compounds in cultivated mushrooms. J Agric Food Chem. 2001;49: 2343-8. [24] Mizuno T, Saito H, Nishitoba T, KaWagishi H. Antitumor active substances from mushrooms. Food Reviews International. 1995;11: 23-61.

[25] Wang H, Liu W, Ng TB et al. The immunomodulatory and antitumor activities of lectins from the mushroom Tricholoma mongolicum. Immunopharmacology. 1996;31: 20511.

[26] Grube BJ, Eng ET, Kao YC et al. White button mushroom phytochemicals inhibit aromatase activity and breast cancer cell proliferation. $J$ Nutr. 2001;131: 3288-93.

[27] Chen S, Oh SR, Phung S et al. Anti-aromatase activity of phytochemicals in white button mushrooms (Agaricus bisporus). Cancer Res. 2006;66: 12026-34.

[28] Jiang J, Slivova V, Sliva D. Ganoderma lucidum inhibits proliferation of human breast cancer cells by down-regulation of estrogen receptor and NF-kappaB signaling. Int $J$ Oncol. 2006;29: 695.

[29] Liu F, Ooi V, Chang S. Free radical scavenging activities of mushroom polysaccharide extracts. Life Sci. 1997;60: 763-71.

[30] Thyagarajan A, Jiang J, Hopf A et al. Inhibition of oxidative stress-induced invasiveness of cancer cells by Ganoderma lucidum is mediated through the suppression of interleukin-8 secretion. Int J Mol Med. 2006;18: 657.

[31] Bjorge T, Lukanova A, Tretli S et al. Metabolic risk factors and ovarian cancer in the Metabolic Syndrome and Cancer project. Int J Epidemiol. 2011;40: 1667-77.

[32] Shimada Y, Morita T, Sugiyama K. Eritadenine-induced alterations of plasma lipoprotein lipid concentrations and phosphatidylcholine molecular species profile in rats fed 
cholesterol-free and cholesterol-enriched diets. Biosci Biotechnol Biochem. 2003;67: 9961006.

[33] Merritt MA, Cramer DW, Vitonis AF et al. Dairy foods and nutrients in relation to risk of ovarian cancer and major histological subtypes. Int J Cancer 2013;132: 1114-24. 